\title{
Identidade e Memória Coletiva como suporte do Design de Mobiliário Urbano
}

\author{
Identity and Colletive Memory as Support for Urban Furniture Design
}

MIRANDA, Adriana; Dr; Universidade Federal do Rio Grande do Sul/UFRGS

adriana.eckert@ufrgs.br

\begin{abstract}
Resumo
No design do mobiliário urbano, além do estudo da ergonomia, dos materiais, da forma e função associam-se os parâmetros de inserção, de interferência, apropriação e legibilidade, que respondem as próprias características dos espaços urbanos e as demandas da sua população.

Enfocamos neste trabalho as relações de identidade e memória da população e do espaço, elucidando os atributos para a projetação e revitalização do mobiliário urbano e construindo uma base de informações para a salvaguarda de remanescentes históricos e para a pesquisa em design.

O objeto de pesquisa concentra-se em praças históricas de cidades de origem imigratória no sul do Brasil, no qual a identidade local, a tradição e a memória são presentes no uso e apropriação e, são, portanto, passíveis de serem detectados por meio da investigação.
\end{abstract}

Palavras Chave: mobiliário urbano; design e identidade; memória;

\begin{abstract}
In urban furniture design, besides the study of ergonomics, materials, form and function, the parameters of insertion, interference, appropriation and legibility are associated with the characteristics of urban spaces and the demands of their population.

We focus on this work the relations of identity and memory of population and space, elucidating the attributes for the design and revitalization of urban furniture and building an information base for the safeguarding of historical remnants and for design research.

The research focuses on historic squares of cities of immigrant origin in southern Brazil in which local identity, tradition and memory are present in the use and appropriation and are therefore likely to be detected through research.
\end{abstract}

Keywords: urban furniture; design and identity; memory; 


\section{Introdução}

A valorização do passado dos lugares e da sua pesquisa em instituições de memória (museus arquivos ou bibliotecas) são questões cada vez mais reconhecidas em investigações relacionadas à ação projetual em design. A abordagem da identidade e da memória das cidades estão presentes em estudos que buscam contribuir para a salvaguarda dos equipamentos e elementos urbanos bem como dos espaços públicos com valor histórico e cultural.

Assim, uma questão se impõe: o estudo da identidade e da memória de uma comunidade pode contribuir para o design de revitalização de seus espaços públicos? Atividades tradicionais de uma praça, que é ou foi palco de desfiles, festas comunitárias e feiras, podem induzir a projetação de novos elementos ou mesmo promover a adequação dos equipamentos de mobiliário? Ou ainda: os hábitos culturais influem sobre os elementos instalados no espaço público?

Neste sentido, este trabalho, aborda especificamente praças de cidades de origem imigratória, onde os aspectos de memória coletiva e de identidade a priori, são mais facilmente detectáveis.

Ao mesmo tempo, em um mundo cada vez mais globalizado, a padronização fica cada vez mais evidente quando falamos de mobiliário urbano. Francisco, Ruivo e Almendra argumentam que a "excessiva homogeneização do mobiliário contribui para a progressiva perda de identidade cultural das cidades" (2015, p. 2). Assim, estudos que propõe revelar as tradições e dinâmicas dos espaços públicos culturalmente diferenciados detectariam aspectos significativos e singulares, propondo uma projetação mais consciente e justa do mobiliário urbano, onde questões como pertinência, relevância, interferência e identificação seriam contempladas com respeito ao usuário e a cidade.

O espaço público da praça é o palco de atividades de lazer e de eventos da comunidade. Por isso, seu valor e a sua permanência invoca a sensação de pertencimento e de lugar de memória. Além disso, a memória coletiva de uma comunidade contribui para a formação da identidade da mesma, cujos laços comuns podem, por sua vez, estar vinculados a lugares.

O conceito de memória em vários níveis foi estudado pelo sociólogo francês Maurice Halbwachs (2003). Na memória coletiva, Halbwachs aborda a indissociação do tempo e do espaço. A memória só se concretiza quando encontra a materialidade do espaço. Nesta relação ele comenta:

\footnotetext{
O lugar ocupado por um grupo não é como um quadro negro no qual se escreve e depois se apaga números e figuras. Como a imagem do quadro negro poderia recordar o que nele traçamos, se o quadro negro é indiferente aos números e se podemos reproduzir num mesmo quadro as figuras que bem entendemos? Não. Mas o local recebeu a marca do grupo, e vice-versa. Todas as ações do grupo podem ser traduzidas em termos espaciais, o lugar por ele ocupado é apenas a reunião de todos os termos. Cada aspecto, cada detalhe desse lugar tem um sentido que só é inteligível para os membros do grupo, porque todas as partes do espaço que ele ocupou correspondem a outros tantos aspectos diferentes da estrutura e da vida de sua sociedade, pelo menos o que nela havia de mais estável (2003, p.159).
}

Castello também ressalta que o uso que as pessoas fazem do ambiente construído ao longo do tempo confere status diferenciado aos lugares urbanos, e que, a associação de lugar com a passagem do tempo considera que existe, para a noção de lugar, fenômenos associados com a história e a memória das cidades (2007: p.22).

Ao tratar da memória coletiva, Le Goff esclarece que, como manifestações significativas a partir do 
século XIX e início do XX, ocorrem dois fenômenos: o primeiro, logo depois da 1a Guerra Mundial que é a construção de monumentos aos mortos. Um exemplo em vários países é a construção dos Túmulos ao Soldado Desconhecido, proclamando sobre um cadáver sem nome a coesão da nação em torno da memória comum. O segundo é a fotografia, que revoluciona a memória: multiplica-a e democratiza-a, concedendo uma verdade visual nunca antes atingidas, guardando a memória do tempo e da evolução cronológica. (2003,p.460)

Estes fenômenos destacados por Le Goff, reforçam a importância dos marcos urbanos, das imagens da cidade, do mobiliário e seus espaços públicos para a valorização do seu patrimônio e da história coletiva. Para a pesquisa da cidade, a fotografia possibilita a compreensão da transformação dos seus espaços e muitas vezes dos hábitos e tradições da sua população, evidenciando alguns aspectos identitários significativos.

Ao focarmos na pesquisa, grupos de cidades de mesma origem imigratória, cujos indivíduos seriam conscientes de uma cultura comum, estamos verificando as questões que envolvem a inserção, uso, apropriação, permanência e a tradição (vinculada a memória) que incide no mobiliário urbano. De maneira semelhante, Francisco, Ruivo e Almendra, consideram o mobiliário como mediador entre o usuário e a cidade, podendo promover ou não a cultura do lugar. Assim, as autoras consideram como parâmetros de identidade: padrões; memórias; formas; materiais; localização e permanência e a valorização de uma função $(2015$, p. 11).

Salientamos que a identidade dos lugares não é muitas vezes evidente. Para Brandão, que trata da relação de identidade e espaço, a falta de clareza desta questão teria diferentes origens, mas ele salienta que a memória e a identidade são valores subjetivos, e que os agentes envolvidos (administração, técnicos, investidores) teriam diferentes percepções com prioridades difíceis de valorar (2008, p.12).

Para este trabalho, contudo, os reflexos de identidade nos espaços públicos estudados partem dos referenciais históricos do grupo descendente imigrante, da trajetória da construção do espaço e das ações ou atividades desta comunidade no lugar.

Isto de certa forma é compactuado por Brandão, quando ele comenta sobre o conceito de identidade trazido pela psicologia social e ambiental: a territorial (limites), a comportamental (práticas), a social (estilo de vida) e aquela temporal (história comum) (2008, p.13). Já a memória de um grupo e a crença em uma origem comum, relembra e difunde hábitos tradicionais, religiosos e comunitários marcando os espaços de reunião e, naturalmente seus espaços públicos.

Assim, o significado de um espaço estaria vinculado às suas formas de uso. Neste sentido, a apropriação, como conceito, estaria relacionada aos novos significados atribuídos a um lugar e os seus elementos, ou mesmo os novos usos. Da mesma forma, seria inerente a conduta dos usuários: quanto mais a utilização é demandada melhor seria a conservação, manutenção e adequação, sendo que o contrário levaria ao abandono, ao vandalismo e ao descaso.

Neste trabalho, a análise de dois casos de praças, parte de um estudo mais amplo em andamento que aborda também outras origens imigratórias. O estudo dessas praças é pertinente na medida que esses espaços públicos possuem valor histórico e, portanto, poderão fazer parte de processos de revitalização nos quais se demandaria a projetação de novos mobiliários e reinserção de remanescentes. 


\section{0 método e a técnica da pesquisa}

O objetivo principal da pesquisa é o estudo do mobiliário urbano em praças históricas, a fim de se conhecer os valores intrínsecos ou construídos (de identidade, memória coletiva, de uso) junto a população e subsidiar possíveis ações de preservação e reabilitação, que envolveriam o design de mobiliário. Para a pesquisa, observamos os métodos de estudo das RACs ou Relações Ambiente Comportamento ${ }^{1}$. Conforme Ornstein, Bruna e Romero (1995), estes estudos possuem um caráter interdisciplinar e buscam elucidar as relações biunívocas entre ambiente construído e o comportamento dos seus usuários. Ao focar o mobiliário urbano de praças históricas de cidades de origem imigratória, consideramos grupos usuários no qual a tradição e memória estarão presentes no uso e apropriação, e passíveis de serem detectados por meio da pesquisa.

Salientamos que na maior parte das praças do Brasil, a eleição do mobiliário urbano é realizada por meio de processos licitatórios de empresas que possuem catálogos de produtos disponíveis no mercado e que, não são necessariamente aqueles adequados as atividades demandadas aos espaços, quanto mais dizer, da realidade cultural desses locais. Assim, é preeminente as abordagens de contexto, onde sejam considerados os aspectos locais para o design.

As praças enfocadas neste artigo correspondem a dois espaços públicos de duas cidades com origem imigratória germânica do estado do Rio Grande do Sul, Brasil: a Praça Concórdia da cidade de Ivoti e a Praça do Imigrante de São Leopoldo. Ambas possuem entorno com edificações de valor histórico e são lugares públicos tradicionais. Além disso, são reconhecidos historicamente como espaços agregadores dos cidadãos por seus marcos históricos (monumentos) ou atividades e festas tradicionais (kerbs ${ }^{2}$ e feiras).

Através de visitas locais foram adotados os seguintes procedimentos de RAC para o estudo dos equipamentos e mobiliário das praças:

a) Levantamento físico: a partir de planta cadastral, localizamos a inserção do mobiliário urbano da praça, verificando suas dimensões e aspectos ergonômicos;

b) Levantamento fotográfico;

c) Observação do desempenho físico: condições de degradação e manutenção do mobiliário;

d) Observação do comportamento dos usuários: como os usuários utilizam a praça e seu mobiliário; hábitos comuns aos seus frequentadores; apropriações;

e) Entrevistas: realizadas com pessoas chave: usuários habituais; vizinhança; funcionários da prefeitura; líderes comunitários. Em entrevistas abertas.

f) Pesquisa documental em arquivos públicos e privados: pretende esclarecer - através de documentação fotográfica e outros, as trajetórias das praças;

\footnotetext{
${ }^{1}$ Os estudos neste sentido, interdisciplinares, tiveram sua origem na psicologia ambiental e verificam em que medida o ambiente afeta o comportamento e vice-versa. (Ornstein, S.;Bruna, G.; Roméro,M. Ambiente construído e comportamento: avaliação pós-ocupação e qualidade ambiental. Studio Nobel:FAUUSP:FUPAM,1995.)

${ }^{2}$ Festa tradicional em núcleos de origem germânica. Remete a eventos de inauguração de igrejas, ou homenagem a padroeiros da comunidade. Após da missa ou culto, uma bandinha saudava os presentes, conduzindo-os ao salão de baile, onde iniciavam as festas familiares e bailes que costumavam progredir por três dias. Em Ivoti é comemorado em janeiro. Ver KREUTZ
} 
A partir desses procedimentos, foram organizados fichamentos do mobiliário urbano e da praça. Estes fichamentos constituíram uma base cadastral que subsidiaram a análise e diagnóstico do mobiliário urbano nas praças permitindo o embasamento necessário para a elaboração de futuros editais de projeto e o próprio processo de projetação. Além disso, considerando-se preexistências atuais e históricas do mobiliário, a base cadastral servirá, por si só, como fonte de informações para o estudo do design, do desenvolvimento tecnológico, da cultura material e da evolução dos objetos.

Reforçamos que, ao enfocarmos os aspectos de identidade - neste caso, a cultura imigrante de origem e de colonização - e a memória, relacionada ao espaço e seus objetos, estaremos contribuindo para o design de mobiliário mais próximo com a realidade cultural destas comunidades que buscam manter as suas referências no contexto multifacetado do sul do Brasil.

\section{Praça Concórdia e seus elementos de mobiliário}

A Praça Concórdia é a mais antiga da cidade de Ivoti, com população de aproximadamente 20.000 habitantes. A data da sua inauguração foi em 1959, ainda quando Ivoti pertencia ao município de São Leopoldo. Trata-se de uma praça localizada ao longo da principal avenida da cidade, cujo traçado foi resultado do sistema de ocupação territorial de imigração alemã no Rio Grande do Sul, em que as chamadas "picadas" conectavam as propriedades rurais que foram se formando a partir de 1824, data oficial da chegada dos primeiros grupos de imigrantes.

A Praça Concórdia divide-se em duas partes por uma rua transversal: uma seção congrega a maior parte da sua área, e é intensamente arborizada, enquanto a outra metade é pavimentada e conta com um chafariz.

Justamente em frente à praça, localiza-se uma das principais sociedades históricas da cidade e aquela que traz seu nome: a Sociedade Concórdia. As sociedades de Ivoti nasceram da necessidade dos colonos de manter um ponto de encontro para a vida social e cultural da cidade. Tradicionalmente, os encontros sociais na colônia - a exemplo dos Kerb já citados- aconteciam em casas particulares e em salões espaçosos. Com o passar dos anos, foram fundadas as sociedades entre elas a Concórdia e a Harmonia - clubes que promoviam bailes, atividades dos corais e da prática do bolão.

Acontece ainda na avenida, todo mês de julho, entre a Sociedade Concórdia e a Praça de mesmo nome, a famosa Festa do Colono ou a Kolonistenfest, realizada para a integração de todas as comunidades do município em homenagem ao imigrante. $O$ desfile alegórico comemorativo se desenvolve ao longo da avenida e em frente à praça, difundindo a história colonial e a cultura local. 
Em termos de configuração, a praça teve três momentos significativos: aquele da inauguração, onde foi construído um marco comemorativo; o da primeira reforma de 1973, onde foram instalados banheiros, bancos de madeira artesanais e brinquedos de playground; e por fim, aquele da praça atual, reformada em 2004 por meio de um projeto de arquitetos não locais.

Figura 1 - Sociedade Concórdia

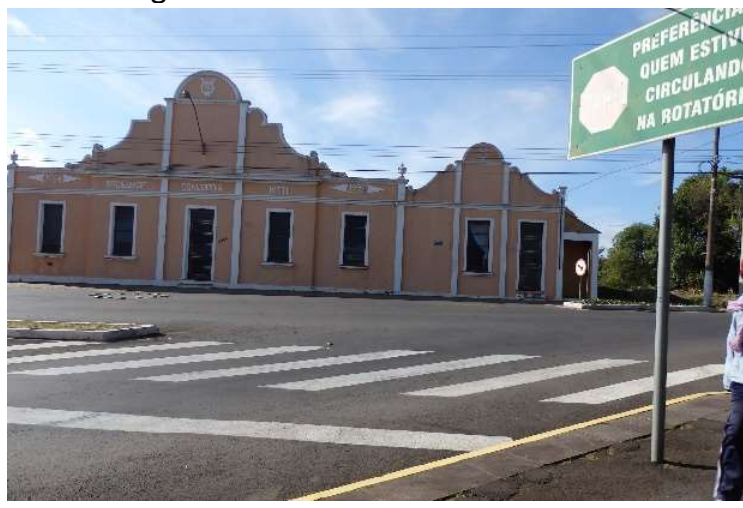

Fonte: Autor, 2016.
Figura 2 - Desfile Festa do Colono

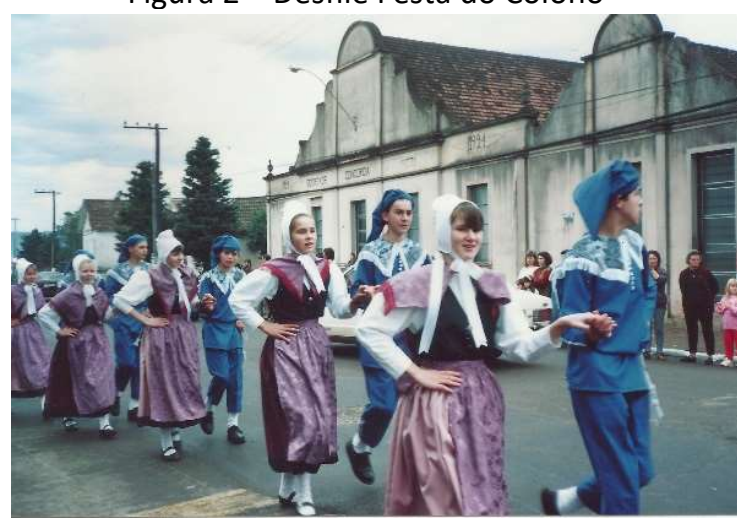

Fonte: Arquivo Prefeitura de Ivoti

Da praça original, só obtivemos as imagens da inauguração e do seu marco, construído como um pedestal de alvenaria. Já ao período da segunda fase, nos arquivos da Prefeitura, constam uma fotografia do desfile na Festa do Colono e da própria Praça, antes de 2004. Nesta, que é uma imagem noturna, podemos reconhecer alguns dos seus antigos elementos de mobiliário bem pintados e conservados, com farta iluminação decorativa para o Natal.

Atualmente, na área principal da Praça Concórdia, o playground foi suprimido. A atividade de ginástica é a principal atração, com equipamentos próprios. Eles são constantemente requisitados pelos adultos usuários e até pelas crianças. Verificamos, em entrevistas, que a ginástica é uma atividade mantida pela prefeitura e muito difundida principalmente entre os idosos da comunidade, que são assíduos em programas da prefeitura para a terceira idade no local. A ginástica, apesar de não se constituir em uma atividade relatada pelos primeiros colonos, encontrou repercussão entre seus descendentes no estado ainda no século XIX. Tinha lugar nas chamadas "sociedades de ginástica" fundadas em algumas localidades e, no caso de Ivoti, pela difusão de programas de atividade física pela comunidade. Esta tradição teve origem na sistematização dos exercícios físicos ainda no século XVIII, na Alemanha assim como na França e Suécia e, como descreve Evelise Quitzau, estas escolas apresentavam "a crença na necessidade de regeneração da população; a ideia de uma relação direta entre corpo e mente, bem como do uso do exercício físico como instrumento para a educação moral e a preparação para a defesa da pátria" (QUITZAU, 2015,p.112). O movimento e o termo turnen (termo para ginástica) difundiu-se no sul do Brasil através das sociedades teuto-brasileiras e dos seus personagens. Seyferth coloca essas sociedades como instituições que, mais que promover a ajuda mútua ou outro tipo de atividade recreativa, "tomam para si a função de propagadoras e conservadoras da cultura germânica" (1999,p.26). Em 1896, seis sociedades de ginástica (Turnverein) do estado participaram de um torneio na capital Porto Alegre e, nos anos seguintes, outras muitas fariam parte de uma liga, disseminando a prática em muitas comunidades de origem germânica (LEVIEN, 2011,p.24). Ressaltamos que na Praça Concórdia, embora os equipamentos de ginástica sejam padronizados (de catálogo) a instalação e manutenção desse tipo de equipamento se justifica pela 
tradição envolvida e o afluxo de usuários, devendo, portanto, ser valorizada.

Outros elementos da praça remetem, sutilmente a relações identitárias: a exemplo dos bancos instalados - de catálogo - e as lixeiras. Ambos construídos em ripas de madeira e armações em ferro, detém o caráter artesanal que remete a tradição colonial da região.

$\mathrm{O}$ artesanato é tradicionalmente uma atividade ligada à produção agropastoril dos colonos e do comércio, tendo seu apogeu entre 1824 e 1890, com declínio no início do século XX no qual acontece a transformação do trabalho artesanal de oficinas para a indústria (ROCHE, 1969). A atividade artesanal então desvincula-se da produção de bens de consumo para fazer parte da herança cultural colonial das comunidades teuto-brasileiras que difundem o artesanato como atração turística.

Isso também pode ser associado a inserção de outros equipamentos. Junto à avenida limítrofe, está instalado o abrigo de ônibus da praça, que se justapõe a outro no lado oposto da via. Neste caso, é perceptível a dicotomia de desenhos: o abrigo na calçada da praça é conceitualmente contemporâneo, por seus atributos materiais, de leveza e forma, enquanto o abrigo da outra margem da avenida assemelha-se à uma edificação, com pilares de concreto e cobertura em telhas de barro. Não se conhece os motivos para a divergência, possivelmente produto de diferentes administrações. Contudo, neste mobiliário é perceptível a presença do artesanal através da edificação in loco e da telha de barro - referenciada pela arquitetura local - em contraponto com a estrutura leve de design contemporâneo.

Figura 3 - Aparelhos de ginástica

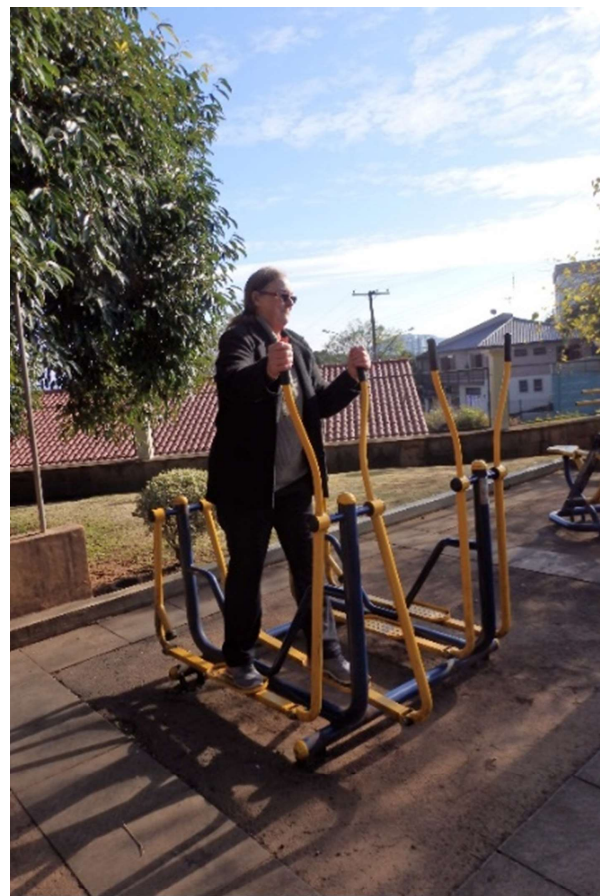

Fonte: Autor, 2016.
Figura 4-Ginástica e diversão

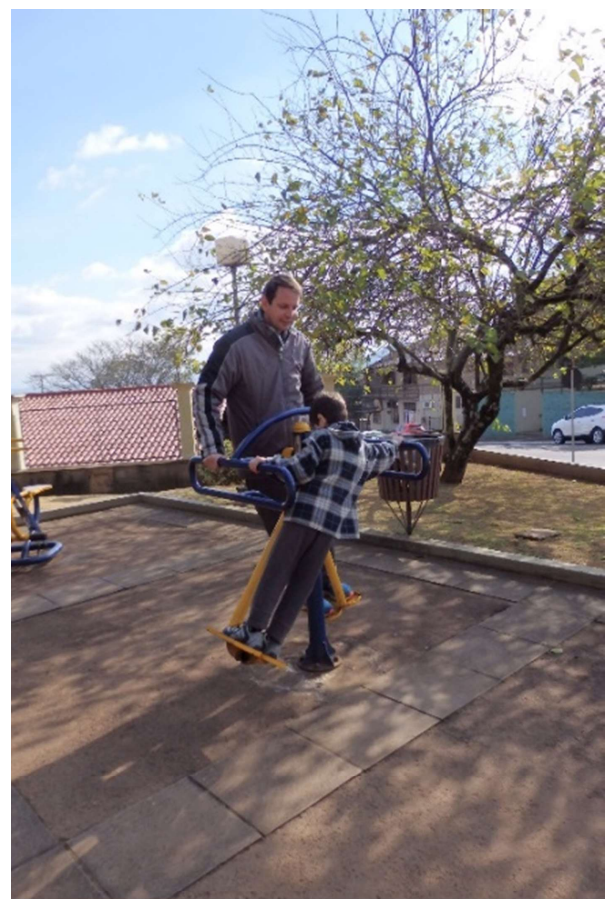

Fonte: Autor, 2016. 
Figura 5 - Abrigo de ônibus/edificação

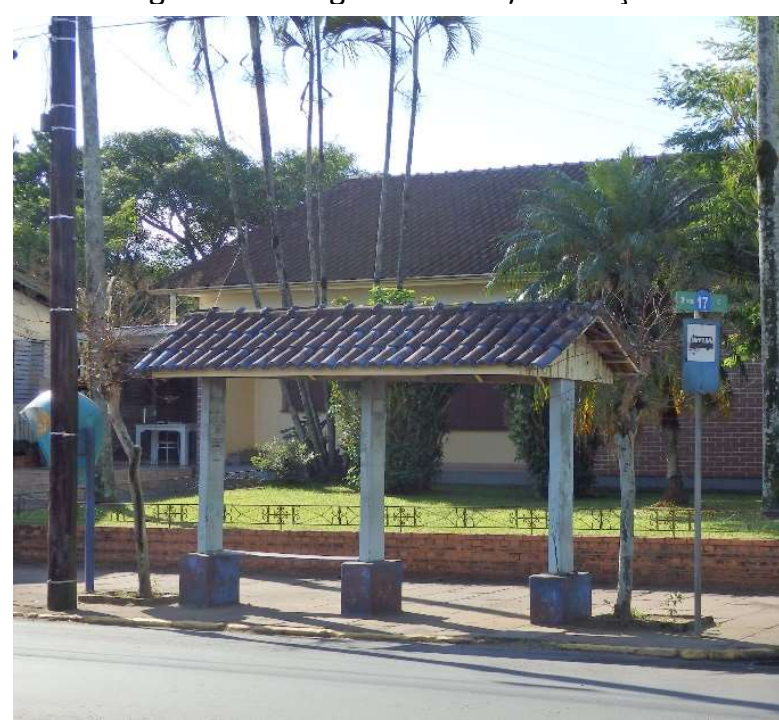

Fonte: Autor, 2016.
Figura 6 - Abrigo ônibus/estrutura leve.

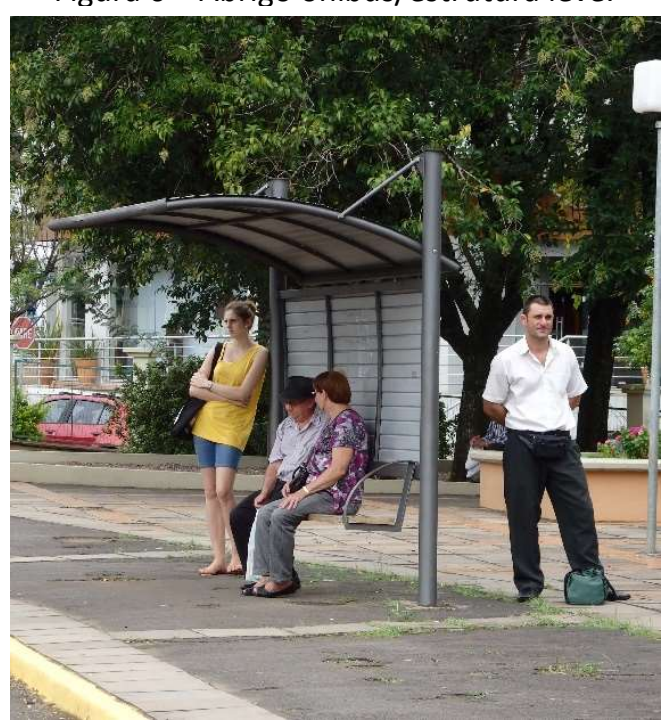

Fonte: Autor, 2016.

Um aspecto importante de assinalar é a presença e a valorização em toda a cidade dos canteiros e floreiras. Para os teuto-brasileiros o cuidado com a casa, a limpeza e a organização é um traço cultural, que se reflete nos seus espaços públicos:

Mas o que dá uma aparência específica à casa do colono, qualquer que seja sua origem, é a presença de um jardim, por mais modesto que se apresente. O jardim na parte da frente da casa e a horta nos fundos costumam ser recorrentes nas propriedades rurais. [...] Nos centros maiores a horta tende a desaparecer, mas o estereótipo do jardim permanece, mesmo quando ele não existe [...] na verdade, a presença de uma pequena área destinada ao cultivo de flores, na frente da casa, é um costume mantido nas regiões de imigração, costume particularmente cultivado por teuto-brasileiros (SEYFERTH, 1990,p.47).

Essa tradição na Concórdia é percebida nos canteiros de manutenção cuidadosa, com a reposição de flores e folhagens e a limpeza dos mesmos.

Na outra seção da praça, o espaço é definido por uma extensa área pavimentada, própria para atividades artísticas e outros eventos. Encontram-se nesta área bancos e uma arquibancada em alvenaria com três níveis. Apesar desta atividade ser pertinente às demandas festivas da cidade e desfiles na avenida, os comentários, em entrevista, são de que o espaço é mais utilizado nos finais de semana para descanso e contemplação.

Equipamentos como os banheiros e arquibancadas respondem às demandas das festas tradicionais e desfiles. Contudo, cotidianamente, as atividades atratoras ficam restritas à ginástica, cujos equipamentos padronizados atendem essencialmente ao uso adulto, mas não ao grupo infantil. 
Figura 7 - Arquibancadas

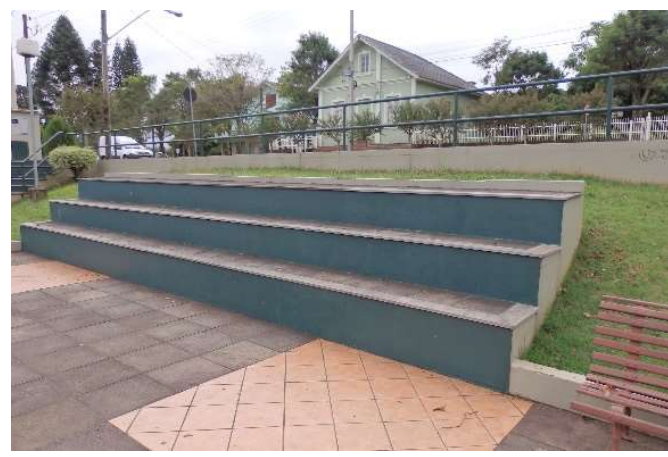

Fonte: Autor, 2016.
Figura 8 - Bancos de catálogo

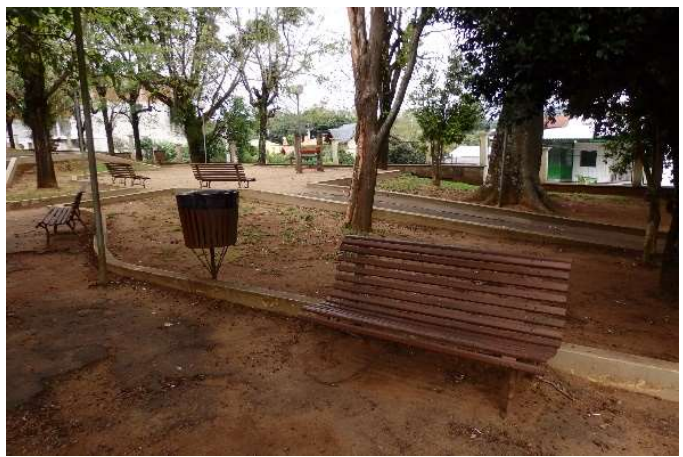

Fonte: Autor, 2016.

\section{Praça do Imigrante e seus elementos de mobiliário}

O atual município de São Leopoldo, como já mencionado, foi o local de desembarque dos primeiros imigrantes alemães em 1824. Este desembarque teria acontecido justamente no local da atual Praça do Imigrante, junto ao Rio dos Sinos. A importância deste evento foi comemorada 100 anos depois, com um imponente monumento, que marca o centro deste espaço, congregando a sua população em muitos momentos da sua trajetória pública, conforme a pesquisa de imagens em arquivos.

Além do monumento, o Rio dos Sinos, a ponte 25 de Julho, edifícios institucionais tombados e inventariados envolvem a praça, compondo marcos e limites configuracionais que denotam o valor histórico daquele espaço público. Isso também pode ser facilmente reconhecido através de imagens de eventos diversos e do perímetro tomado pelo Memorial de Tombamento da Praça do Imigrante (Conselho Municipal do Patrimônio Histórico, 2012), que abrange a área da praça e seu entorno.

Diferente da Praça Concórdia, a Praça do Imigrante sofreu um processo de perda de importância e de descaracterização progressiva. Isto, a princípio, ocorreu devido ao crescimento populacional significativo de São Leopoldo junto à Região Metropolitana de Porto Alegre ao longo do século XX. Como a praça encontra-se em um dos principais acessos da cidade e junto à rodoviária, houve o gradual alargamento e concentração de vias, prejudicando as conexões do pedestre em favor do tráfego.

Figura 9 -Praça do Imigrante 1934

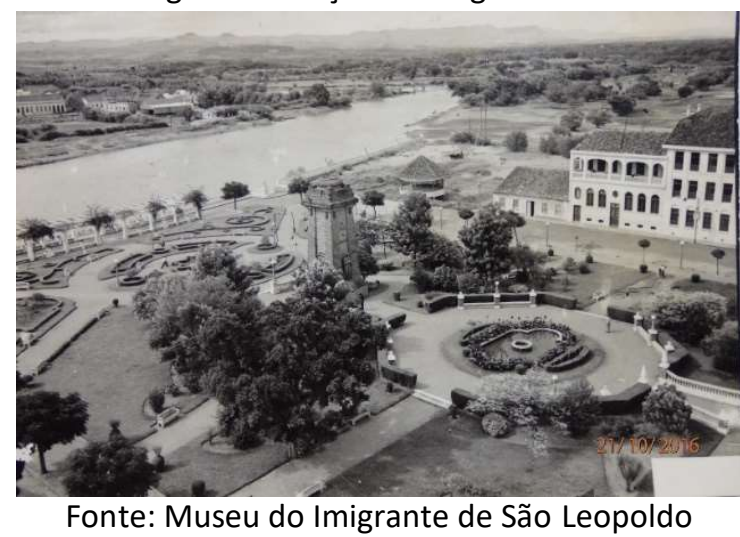


Organizamos o quadro a seguir com os atributos do espaço dados a partir do levantamento no local, dos relatos e do acervo documental da praça:

Quadro 1 - Elementos e Atributos

\begin{tabular}{lll}
\hline $\begin{array}{l}\text { Elementos } \\
\text { espaciais/eventos }\end{array}$ & $\begin{array}{l}\text { Atributos tradicionais e antigos } \\
\text { (1) metade do séc. } \mathbf{X X )}\end{array}$ & Atributos atuais \\
\hline Rio & $\begin{array}{l}\text { Valorização das visuais: pergolado para } \\
\text { contemplação; }\end{array}$ & $\begin{array}{l}\text { Dique de contenção do rio que funciona como } \\
\text { barreira; poluição; }\end{array}$ \\
\hline Igreja & Acesso direto em frente à praça & Sem acesso pela praça \\
\hline Escadarias & $\begin{array}{l}\text { Acesso direto ao rio e a ponte; iluminação } \\
\text { pedestre; balaustradas; }\end{array}$ & $\begin{array}{l}\text { Sem acesso ao rio (dique); acesso à ponte por } \\
\text { escadaria simples; }\end{array}$ \\
\hline $\begin{array}{l}\text { Feiras } \\
\text { Comemorações }\end{array}$ & Feira do Peixe; feira Vale Tudo; & Feira do Peixe; feira Vale Tudo; \\
\hline $\begin{array}{l}\text { relativas } \\
\text { imigração/cívicas }\end{array}$ & Ocorriam junto ao monumento; & Não ocorrem; \\
\hline
\end{tabular}

Fonte: Autor,2017.

Percebe-se através do quadro, que a Praça do Imigrante possuía interações importantes com a cidade e o rio, qualificadas através do mobiliário instalado que a tornava um espaço público vivo da cidade e significativo em função da memória imigrante - dada pelo monumento e suas celebrações e pelas feiras no local. Porém, como podemos verificar em entrevistas e na observação local, os eventos e parte dos atrativos inexistem nos dias de hoje com significativa perda qualitativa.

O mobiliário por sua vez, guarda alguns remanescentes, como é o caso dos bancos originais móveis e daqueles que compõe estruturas lineares para sentar. Nas imagens antigas, verifica-se a distribuição criteriosa do mobiliário, contribuindo para o desenho da praça que privilegiava o monumento ao Imigrante como ponto focal principal. A memória da praça e seus elementos de

Figura 10 - Evento de ginástica na década de 30

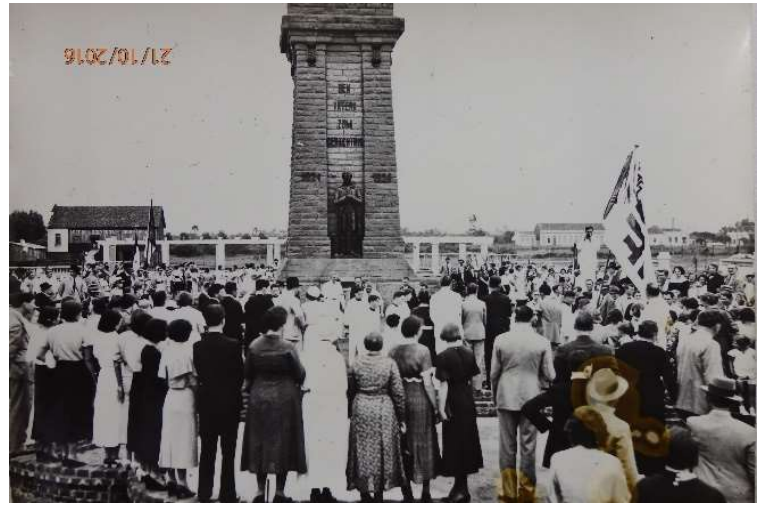

Fonte: Museu do Imigrante de São Leopoldo
Figura 11 - Chafariz na década de 80

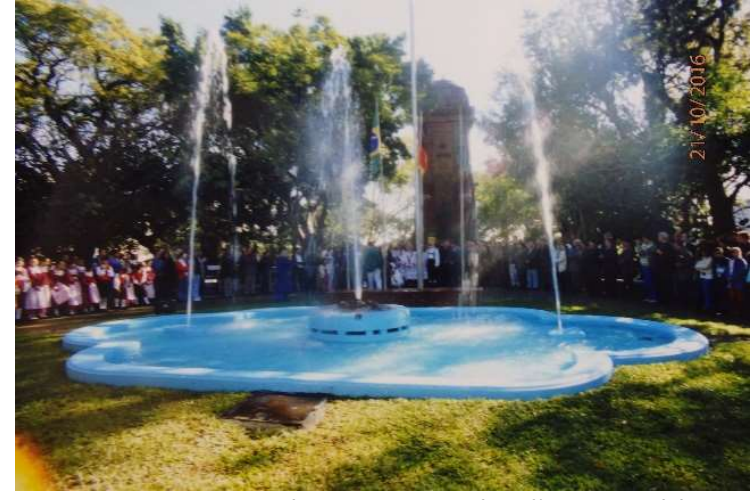

Fonte: Museu do Imigrante de São Leopoldo 
mobiliário foi preservada em várias imagens de acervo.

A partir da pesquisa documental de imagens da praça e das visitas no local organizamos comparativamente os elementos antigos ou originais da fundação e aqueles atuais e remanescentes conforme o quadro abaixo:

Quadro 2-Comparativo mobiliário antigo e atual

\begin{tabular}{lll}
\hline Mobiliário & Antigo/Original & Atual \\
\hline 1. Bancos & $\begin{array}{l}\text { Dois tipos: soltos (concreto e madeira) ou como } \\
\text { assentos em linha, definidores da geometria de } \\
\text { alguns espaços; }\end{array}$ & $\begin{array}{l}\text { Alguns remanescentes soltos (pintados } \\
\text { pelos usuários) e inseridos sem critério; } \\
\text { assentos em linha perduram; banco mais } \\
\text { novos de catálogo (concreto e madeira) }\end{array}$ \\
\hline 2.Postes lluminação & $\begin{array}{l}\text { Instalados a borda do rio e caminhos internos; } \\
\text { Diferenciação no desenho conforme número de } \\
\text { lâmpadas;Ferro fundido e cúpulas em vidro; }\end{array}$ & $\begin{array}{l}\text { Variados tipos; menor número de } \\
\text { iluminação; }\end{array}$
\end{tabular}

\begin{tabular}{lll}
\hline 3. Postes de rede & Sem informações; & $\begin{array}{l}\text { Localizados no perímetro; interferem nas } \\
\text { visuais; concreto; }\end{array}$ \\
\hline 4. Lixeiras & Sem informações; & $\begin{array}{l}\text { Tonéis de aço adaptados; elementos } \\
\text { voláteis; }\end{array}$ \\
\hline 5.Coreto & Não existe; \\
\hline 6. Pergolado & Junto ao rio; bancos e iluminação junto ao rio; & Não existe; \\
\hline 7. Parquímetro & Não existe; & $\begin{array}{l}\text { Equipamento padrão como outros } \\
\text { presentes no centro da cidade; }\end{array}$ \\
\hline
\end{tabular}

8. Sinalização Sem informações;

Presente nas calçadas limítrofes; uma única placa informativa (pouco legível) do nome da praça; sinalização de trânsito;

\section{Chafariz \\ Elemento com contornos curvos, círculo central com jatos ativos; \\ Desativado, supressão do círculo central; caixa de manutenção com significativa interferência na paisagem;}

\section{Estátua religiosa $\quad$ Teria sido instalada em 1940;}

10. Monumento e marco da Imigração
Monumento: Instalado antes da fundação da praça (1924) por ocasião do centenário da imigração; marco central da praça e de comemorações cívicas; Arenito;

Marco: pedra em granito com inscrições que designa a praça com local do desembarque dos primeiros imigrantes;
Elemento de devoção; demonstração apreço da população: manutenção do manto em tecido e flores; pedestal em alvenaria e imagem em cimento;

Monumento: Sofre degradação (vegetação parasita; placas de bronze suprimidas);

Recebe lluminação especial.

Marco: permanece no local sem degradação detectada; 
Através da análise dos quadros, e, especialmente o acima, constata-se que a praça perdeu atributos qualitativos não só com relação aos já mencionados mas também no que tange ao seu mobiliário. Mesmo que o local seja próximo a diversos edifícios públicos, edificações históricas e rodoviária, percebemos que a praça atual não atrai a população como fazia nas suas primeiras décadas. Vimos que a supressão e falta de manutenção de elementos de mobiliário atratores a exemplo do pergolado e do chafariz, e atividades significativas como as feiras, concorreram para o seu isolamento e a sua deterioração como espaço público.

O mobiliário remanescente, que poderia ser restaurado e valorizado por sua presença histórica, sofre com a degradação ou com a intervenção sem critério, como é o caso dos bancos e do chafariz. Os bancos foram pintados pela população com cores chamativas e o chafariz, que sofreu alterações questionáveis, como a pintura em preto e a instalação de caixa de manutenção que interfere na paisagem.

Figura 12 - Banco antigo e intervenção

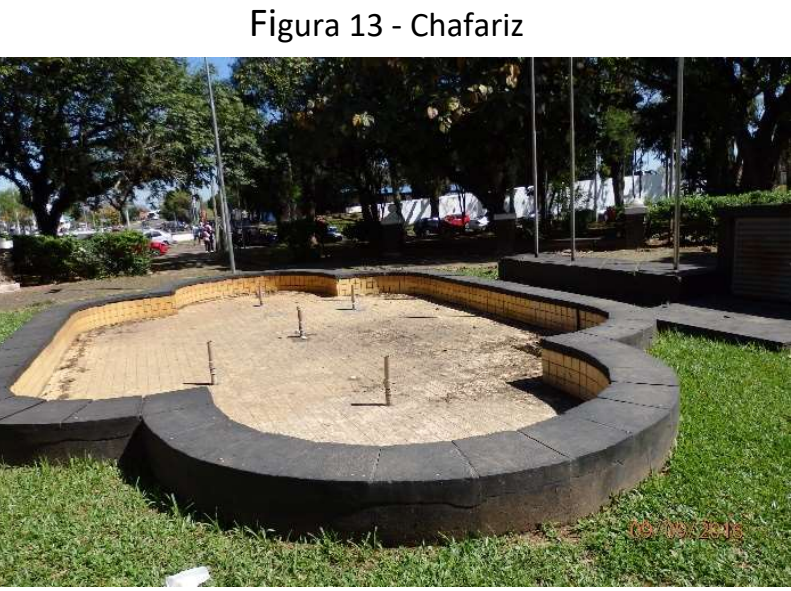

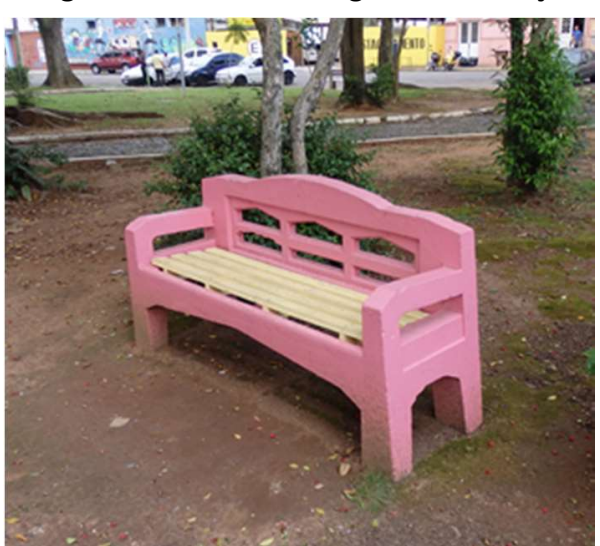

Fonte: Autor, 2017

Fonte: Autor, 2017

Apesar disso, ações no sentido da preservação vêm sido tomadas, muito embora sem considerar as antigas interações que qualitativamente mantinham a afluência de usuários à praça. Dentre essas ações, como comentado antes, está a inclusão da Praça do Imigrante no perímetro do processo de tombamento do centro histórico pelo Instituto do Patrimônio Histórico e Artístico Nacional (IPHAN) e o tombamento, pelo Instituto do Patrimônio Histórico do Estado (IPHAE) da Ponte 25 de julho que é adjacente à Praça. São estabelecidas, portanto, ações de salvaguarda que possibilitarão, no futuro, a reabilitação da praça.

\section{Considerações Finais}

O mobiliário urbano estudado pertence a praças que são marcos urbanos de suas cidades. Contudo, esses espaços como um todo, possuem características bastante distintas com relação ao seu papel histórico e atual junto à comunidade.

Enquanto na Praça Concórdia são identificáveis a manutenção e apropriação do mobiliário proporcionado pelo afluxo de usuários à praça, na Praça do Imigrante temos a sensação de isolamento do tecido urbano, dado pelo tráfego intenso das vias do entorno, um expressivo número de edifícios institucionais e comerciais e a pouca afluência de usuários. Mesmo que se atribua a essa pouca afluência à fatores externos à praça, observamos nas imagens de arquivo 
documental, que a progressiva modificação de atributos originais, como a interação com o rio, com a igreja e a ponte colaboraram para esse isolamento. Soma-se a isso, as modificações do mobiliário urbano original, tais como a supressão do pergolado, da iluminação e a degradação do chafariz que possuía o apreço dos usuários.

Ao mesmo tempo, os bancos antigos foram pintados sem critério, em uma apropriação pela comunidade no sentido da sua preservação.

O valor de memória, contudo, é perceptível através do levantamento documental da Praça do Imigrante, que mostra ao longo dos anos o significado do monumento para a comunidade de origem germânica. Várias comemorações e reuniões ocorreram junto ao monumento em momentos distintos da vida da praça, demonstrando o seu valor histórico e identitário. É um elemento que promove a coesão da comunidade em torno da memória comum.

Já a Praça Concórdia, totalmente remodelada, preserva essencialmente a interação com a Sociedade e a avenida, locais de comemorações e desfiles.

Verifica-se que, enquanto na nova praça Concórdia a manutenção é adequada, graças à municipalidade e ao afluxo e apropriação dos usuários, na praça do Imigrante a deterioração é significativa, dada a perda de interação com o entorno. Mesmo assim, parte do seu mobiliário histórico permanece, exigindo urgência no sentido de repensar os vários aspectos da sua requalificação.

Identificamos ainda que falta, para os dois espaços muito além da respeitosa restauração e reabilitação, uma sinalização turística e informativa que valorize a história dessas praças, cuja origem e trajetória relaciona-se com a cultura local. Além disso, com esta pesquisa pudemos verificar que muitas iniciativas programáticas e projetuais se justificariam para a melhoria desses espaços, dadas as suas trajetórias, equipamentos preexistentes e atividades tradicionais da comunidade. Se pensarmos em exemplos possíveis, vemos que a projetação de mobiliário relacionado as festividades de Ivoti ou as esquecidas feiras de São Leopoldo, poderiam resgatar sensivelmente o uso da praça.

Entende-se que a renovação de equipamentos preexistentes e aqueles a serem inseridos, deverão necessariamente contribuir para reforçar e promover a identidade e a cultura do lugar, sendo sempre cuidadosamente estudados.

\section{Referências}

BRANDÃO, P. A identidade dos lugares e a sua representação coletiva. Lisboa: Europress, Lda., 2008.

KREUTZ, R.A.(org) Bom Jardim - Ivoti: no palco da história. Novo Hamburgo: Editora FEEVALE, 2003.

SEYFERT, G. Imigração e cultura no Brasil. Brasília: Editora da UNB, 1990.

QUITZAU, E. A. A ginástica alemã: observações acerca dos primeiros manuais alemães de ginástica. In: Revista Brasileira de Ciências do Esporte, vol.37, p. 111 -118, abr-jun 2015. Disponivel em: <www.rbceonline.org.br>

SEYFERTH, G. As associações recreativas nas regiões de colonização alemã no sul do Brasil:

Kultur e etnicidade. Revista do Imigrante. Publicação do Centro de Estudos Migratórios, a. XII, n. 
34, p. 24-28, maio - ago. 1999.

ROCHE, J. A colonização alemã e o Rio Grande do Sul. vol.I. Porto Alegre: Editora Globo, 1969

LEVIEN, A. L. A., Histórias do Turnen na Leopoldenser Turnverein: Sociedade de ginástica de São Leopoldo. Pelotas: UFPel/ ESEF, 2011. Dissertação de Mestrado.

LE GOFF, J. História e memória. Campinas: Editora da UNICAMP, 2003.

HALBWACHS, M. A memória coletiva. São Paulo: Centauro, 2003.

FRANCISCO, J.M.; RUIVO, I.S.; ALMENDRA, R.A. Sustainable city with inclusive urban equipment methodology and design. In: Sustainable Development Symposium. Lisboa, 15 a 17 jun. 2015. Anais do $5^{\text {th }}$ Annual European Postgraduate Symposium, 2015.p.1-13.

ORNSTEIN, S.; BRUNA, G.; ROMÉRO, M. Ambiente construído e comportamento: avaliação pósocupação e qualidade ambiental. São Paulo: Studio Nobel, FAUUSP/FUPAM,1995.

CASTELLO, L. A percepção de lugar: repensando o lugar em arquitetura e urbanismo. Porto Alegre: PROPAR/UFRGS, 2007.

Fontes Documentais:

Conselho Municipal do Patrimônio Histórico. Memorial de Tombamento da Praça do Imigrante de São Leopoldo: justificativa histórica e iconografia. Biblioteca do Museu Histórico Visconde de São Leopoldo, 24 de maio de 2012. 